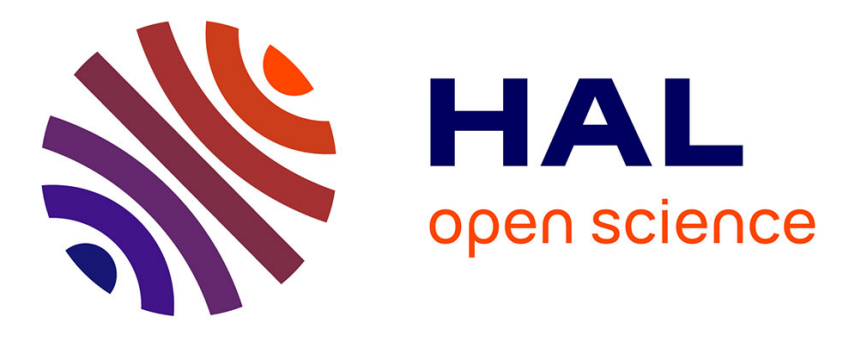

\title{
Enhancement of Cooling Rate by Means of High Frequency Ultrasound
}

Audrey Monnot, Primius Boldo, Nicolas Gondrexon, André Bontemps

\section{To cite this version:}

Audrey Monnot, Primius Boldo, Nicolas Gondrexon, André Bontemps. Enhancement of Cooling Rate by Means of High Frequency Ultrasound. Heat Transfer Engineering, 2007, 28 (1), pp.3-8. 10.1080/01457630600985485 . hal-00270887

\section{HAL Id: hal-00270887 https://hal.science/hal-00270887}

Submitted on 11 Feb 2020

HAL is a multi-disciplinary open access archive for the deposit and dissemination of scientific research documents, whether they are published or not. The documents may come from teaching and research institutions in France or abroad, or from public or private research centers.
L'archive ouverte pluridisciplinaire HAL, est destinée au dépôt et à la diffusion de documents scientifiques de niveau recherche, publiés ou non, émanant des établissements d'enseignement et de recherche français ou étrangers, des laboratoires publics ou privés.

\section{(c)(1)}

Distributed under a Creative Commons Attribution| 4.0 International License 


\title{
Enhancement of Cooling Rate by Means of High Frequency Ultrasound
}

\author{
A. MONNOT \\ LEPMI, UMR 5631 INPG/CNRS/UJF, BP75, 38402 St Martin d'Hères cedex, France \\ P. BOLDO \\ ESIGEC, Université de Savoie, Savoie Technolac, 73376 Le Bourget du Lac cedex, France \\ N. GONDREXON \\ LEPMI, UMR 5631 INPG/CNRS/UJF, BP75, 38402 St Martin d'Hères cedex, France
}

\author{
A. BONTEMPS \\ Université Joseph Fourier, LEGI/GRETh, CEA Grenoble, 38054 Grenoble cedex 9, France
}

Heat transfer in the presence of ultrasound has been investigated. Experiments were performed using a specific experimental setup involving a homemade, high-frequency, ultrasonic reactor equipped with a cooling helical coil. The aim of this study was to investigate the effect of ultrasound with different frequencies on heat transfer between water contained within the reactor and cooling water flowing through the coil. It has been shown that the presence of the ultrasonic field results in an increase of the cooling rate due to an enhancement of the overall heat transfer coefficient of the coil by up to 100\%, depending on operating parameters.

\section{INTRODUCTION}

Heat transfer processes are widely used in many industrial applications, such as in chemical, gas, oil, and food industries. Decreasing heat losses and increasing efficiency of the energy transfer processes are of major importance from both economic and ecological viewpoints. Among the new technical solutions that must be developed and optimized in order to improve heat transfer processes is the application of ultrasonic waves. Although the influence of ultrasound on heat transfer has already been reported in the literature, it is interesting to note that all previous studies have been carried out using waves in the lowfrequency range; no work has been published on the application of a high-frequency ultrasonic field.

\section{PREVIOUS STUDIES}

Ultrasound refers to waves with frequencies ranging from $16 \mathrm{kHz}$ (human hearing threshold) to $10 \mathrm{MHz}$. The broad clas-

Address correspondence to Professor Andre Bontemps, Université Joseph Fourier, LEGI/GRETh, CEA Grenoble, 38054 Grenoble cedex 9, France. E-mail: Andre.Bontemps@cea.fr sification of ultrasonic waves has been divided into two distinct regions, as illustrated in Figure 1 power ultrasound between 20 and $100 \mathrm{kHz}$ and diagnostic ultrasound between 1 and $10 \mathrm{MHz}$.

The propagation of power ultrasound in a liquid results mainly in cavitation and acoustic streaming. Cavitation is generally defined as the formation of small bubbles due to local pressure decrease and their subsequent growth and collapse. The implosion of these bubbles near solid surface results in a microscopic hydrodynamic phenomenon such as micro-jet formation or micromixing of the liquid. Acoustic streaming refers to strong convective currents that occur when a liquid is subjected to an ultrasonic field. These convective currents also induce an overall mixing of the liquid $[1,2]$.

The influence of ultrasound on heat transfer processes has been investigated and reported in several previous works [313]. All of these studies have been carried out using ultrasound operating at a low frequency $(20-69.2 \mathrm{kHz})$ by applying an ultrasonic power ranging from 24 to $600 \mathrm{~W}$. Because these studies have been performed with quite different experimental setups (e.g., frequency, ultrasonic power, heat transfer process), it is difficult to compare the corresponding results from one study to the others. However, the experimental approaches that have been developed can be divided into three main types: 


\begin{tabular}{cc|c|c}
$20 \mathrm{kHz}$ & $100 \mathrm{kHz}$ & $1 \mathrm{MHz}$ & $100 \mathrm{MHz}$ \\
\hline & Power uttrasound & Low power ultrasound & frequency. \\
\hdashline Low frequeney & High frequency & Very high frequeney
\end{tabular}

Figure 1 Usual classification of ultrasound.

1. the effect of ultrasonic vibration on natural convection heat transfer [3-5],

2. the study of phase-change heat transfer by acoustic field application [6-9],

3. the influence of ultrasound on heat exchange process in heat exchangers [10].

In all cases, the influence of experimental parameters (e.g., ultrasonic power, frequency, nature of the material) has been investigated with the aim to quantify the effect of the presence of ultrasonic waves on the heat transfer process. It has also been concluded that the application of ultrasound results in an enhancement of the heat transfer, regardless of the heat transfer mode (e.g., natural convection, phase change heat transfer). Moreover, it has been demonstrated that increasing the ultrasonic power leads to an increase of the ultrasonic enhancement. Furthermore, owing to previous studies devoted to the influence of the frequency, it seems that the lower the operating frequency, the higher the ultrasonic enhancement [2].

The only study related to the use of high frequency ultrasound was initiated in 1994 by Renaudin in order to validate the cooling rate in a sonochemical reactor she had designed [12]. This reactor operates with ultrasound at $500 \mathrm{kHz}$ and a maximal power input of $100 \mathrm{~W}$. The temperature of the liquid within the reactor is controlled by means of a cooling coil placed into the reactor. This work also demonstrated that high-frequency ultrasonic fields increase the overall heat transfer coefficient up to 37 -fold.

All of previous works reported in the literature have shown that in the presence of an acoustic field, the heat transfer process can be greatly enhanced. In all cases, the proposed explanation for such an improvement is related to physical effects induced by the propagation of ultrasonic waves in the liquid. All of these effects create disturbances in the liquid that cause an increased heat transfer (e.g., bulk mixing of the liquid, micromixing near the heated surface).

The aim of the present study was then to compare heat transfer with and without high frequency ultrasound. Preliminary experimental results are reported in this paper.

\section{EXPERIMENTAL SECTION}

\section{Ultrasonic Reactor}

Experiments were carried out using a homemade ultrasonic reactor, which is composed of a cylindrical, double-jacketed glass body, the bottom of which is inserted the emitting system. This emitter system is made of a piezoelectric disk and can be easily removed and changed to modify the ultrasound frequency to be $800,600,300$, or $20 \mathrm{kHz}$. The reactor volume is three liters.

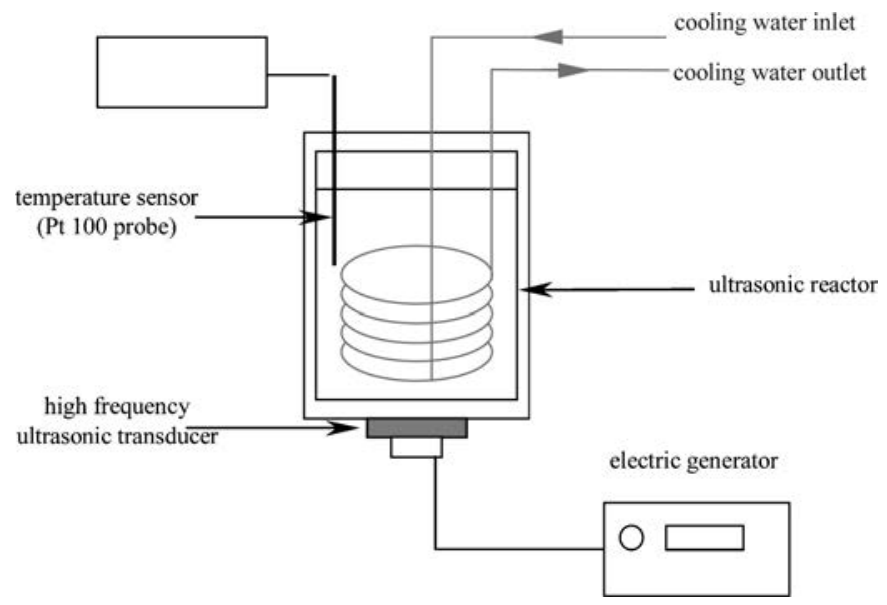

Figure 2 Schematic of the experimental setup.

\section{Overall Setup}

The setup schematic is shown in Figure 2. A copper helical coil (length $=2.5 \mathrm{~m}$, internal diameter $=6 \mathrm{~mm}$, external diameter $=8 \mathrm{~mm}$ ) is placed within the ultrasonic reactor. This coil is fed with cooling water from below at a constant volume flow rate. Eight sensors are used to measure and follow the evolution of the operating parameters versus time. Six RTD platinum $100 \mathrm{ohm}$ sensors are used for temperature measurement. Cooling water flow rate is recorded using one or two MacMillian turbine flow meters, depending on low or high flow rates. A data acquisition system composed of two 16-bit digital converters (ADAM) is connected to a laptop computer. An ADAM 4015 is used for RTD temperature sensors, and an ADAM 4018 for the flow meter signal. Data transfer to a computer is done by a classical RS232 serial input using an ADAM 4522. In-house software written in Visual Basic is used to display real time values and store measurement values in an Excel spreadsheet-compatible data file. The real time display contains temperature- and flow rate-measured values together with calculated heat flow rates and overall heat transfer coefficients.

Particular attention is given to the evolution with time of the following parameters:

- temperature of the water that initially filled the reactor at several locations (top, middle, and bottom of the reactor),

- temperature of the cooling water at the inlet of the coil,

- temperature of the cooling water at the outlet of the coil,

- flow rate of the cooling water in the coil.

\section{EXPERIMENTAL PROCEDURE}

Water contained within the ultrasonic reactor is preheated to a constant temperature $\left(40^{\circ} \mathrm{C}\right)$. The corresponding height of water is kept constant during all experiments and is equal to $35.3 \mathrm{~cm}$, which is to say, $2.885 \mathrm{~L}$. The copper coil is initially not filled with cooling water. The experiments start as soon as the coil is 
fed with cooling water at a constant flow rate $\left(141 \pm 2 \mathrm{~L} \cdot \mathrm{h}^{-1}\right)$ defining the initial time $(t=0)$. The cylindrical, double-jacketed glass body remains empty in order to limit the heat transfer exchange between preheated water contained within the reactor and the ambient air. It also reduces any heat losses through the external walls of the reactor. Experiments are carried out under the same experimental conditions with and without ultrasound.

\section{Determination of the Heat Transfer Coefficient}

\section{Energy Balance}

The aim of this study is also to compare the heat transfer between preheated water contained within an ultrasonic reactor and the cooling water flowing through the coil placed inside the reactor, with and without ultrasound. The corresponding heat transfer coefficient $\left(h_{g}^{\prime}\right)$ was estimated by solving the following energy balance in Eq. (1):

$$
W=m C_{p} \frac{d T}{d t}+h_{g} S_{e x t}\left(T-T_{e x t}\right)+h_{g}^{\prime} S_{r e f}\left(T-T_{r e f}\right)
$$

where $\left(T-T_{r e f}\right)$ can be used instead of the LMTD due to the low coil water temperature variation.

\section{Measurement of the Ultrasonic Power}

In the above energy balance, the power induced by ultrasound (W) is required to solve Eq. (1). This ultrasonic power was determined experimentally by means of an improved calorimetric method developed by Boldo et al. [13]. This method is classically used for the calibration of sonochemical reactors to estimate their energy conversion yield.

\section{Heat Transfer Coefficient Calculations}

Once the ultrasonic power in Eq. (1) is known, it is possible to determine the overall heat transfer coefficient of the coil $\left(h_{g}^{\prime}\right)$. Taking into account that the system time constant $\tau$ is defined as:

$$
\tau=\frac{m C_{p}}{h_{g} \cdot S_{\text {ext }}+h_{g}^{\prime} \cdot S_{\text {ref }}}
$$

and that the temperature reached in steady state is given by:

$$
T_{e q}=\frac{h_{g}^{\prime} \cdot S_{r e f} \cdot\left(T_{r e f}-T_{e x t}\right)+W}{h_{g} \cdot S_{e x t}+h_{g}^{\prime} \cdot S_{r e f}}+T_{e x t}
$$

Equation (1) is then solved as:

$$
T(t)-T_{e q}=\left(T_{0}-T_{e q}\right) \exp (-t / \tau)
$$

with $T_{0}$ being the initial temperature.

It is also possible from collected experimental data to calculate and plot for each time $t$ the quantity $\ln \frac{T(t)-T_{e q}}{T_{0}-T_{e q}}=f(t)$.

Assuming the experimental data to be in good agreement with the proposed modeling, the corresponding curve will be a straight line, the slope of which enables one to determine the value of the system time constant $\tau$. It is therefore possible to deduce the value of the overall heat transfer coefficient of the $\operatorname{coil}\left(h_{g}^{\prime}\right)$.

First, write Eq. (2) in the form:

$$
\left(h_{g} \cdot S_{\text {ext }}+h_{g}^{\prime} \cdot S_{r e f}\right)=\frac{C_{p} \cdot m}{\tau}
$$

Next, from Eq. (3), it can be deduced that:

$$
h_{g}^{\prime}=\frac{\left[\left(T_{e q}-T_{e x t}\right) \times\left(h_{g} \cdot S_{e x t}+h_{g}^{\prime} S_{r e f}\right)\right]-W}{S_{r e f} \times\left(T_{r e f}-T_{e x t}\right)}
$$

The overall heat transfer coefficient of the coil is then obtained by substituting in Eq. (6) the experimental values for $T_{\text {ext }}, T_{\text {ref }}$, $T_{z q}$, and the value of the term given on the left-hand side in Eq. (5). According to Eq. (4), calculations of the temperature of the water initially contained within the reactor $T(t)$ can be deduced after integrating the experimentally deduced value of the system time constant $\tau$.

These calculations are performed to ensure that the experimental values are in good agreement with the proposed modeling. A comparison between experimental and calculated curves will also check the validity of the procedure for the determination of the overall heat transfer coefficient of the coil.

\section{RESULTS AND DISCUSSION}

\section{Modeling Validation}

Sample results are shown in Figure 3 that refer to experiments performed with and without ultrasound operating at $800 \mathrm{kHz}$. Calculated curves (the solid and dashed lines) were computed from Eq. (4) following the procedure described earlier. A comparison of the experimental and calculated curves in Figure 3 indicates that the modeling is in good agreement with the experiments. Such a conclusion can also be extended to all other

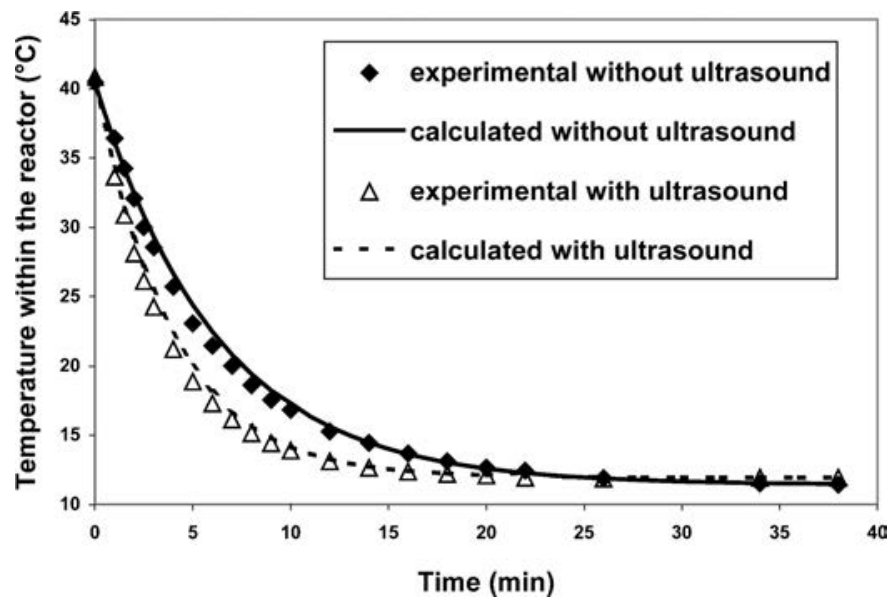

Figure 3 Experimental and calculated temperatures as a function of time with and without $800 \mathrm{kHz}$ ultrasound $\left(W=57.6 \mathrm{~W}, Q=141 \mathrm{~L} \cdot \mathrm{h}^{-1}\right)$. 
Table 1 Example of experimental values of parameters used for the determination of the overall heat transfer coefficient $\left(f=800 \mathrm{kHz}, W=57.6 \mathrm{~W}, Q=141 \mathrm{~L} \cdot \mathrm{h}^{-1}\right)$

\begin{tabular}{llllllll}
\hline & $P_{c a l}(\mathrm{~W})$ & $T_{r e f}\left({ }^{\circ} \mathrm{C}\right)$ & $T_{e q}\left({ }^{\circ} \mathrm{C}\right)$ & $T_{0}\left({ }^{\circ} \mathrm{C}\right)$ & $-\frac{1}{\tau}\left(\mathrm{s}^{-1}\right)$ & $\tau(\mathrm{s})$ & $h_{g}^{\prime}\left(\mathrm{W} \cdot \mathrm{m}^{-2} \cdot \mathrm{K}^{-1}\right)$ \\
\hline Without ultrasound & 0 & 12.17 & 11.42 & 40.47 & -0.1614 & 372 & 582.3 \\
With ultrasound & 57.6 & 12.55 & 11.92 & 40.83 & -0.2555 & 235 & 1079.9 \\
\hline
\end{tabular}

experiments carried out in this work. As a consequence, this makes the method for determining the heat transfer coefficient valid. Detailed results corresponding to experiments performed at $800 \mathrm{kHz}$ are given in Table 1.

\section{Experimental Results and Discussion}

The average values of heat transfer coefficients were estimated from the solution of the heat balance equation. All those values are reported in Table 2.

\section{Comparison with and without Ultrasound}

As it can be seen from values given in Table 2, the heat transfer coefficient of the coil is systematically enhanced by the presence of the ultrasonic field.

Without ultrasound and for given flow rate, the determined overall heat transfer coefficient $h_{g}^{\prime}$ is largely constant (as an example, the average value for $141 \mathrm{~L} \cdot \mathrm{h}^{-1}$ is equal to $580 \mathrm{~W} \cdot \mathrm{m}^{-2} \cdot \mathrm{K}^{-1}$ ). To quantify the effect of ultrasound, an enhancement factor $E F$ is usually defined as the ratio of the value observed with ultrasound divided by the value under silent conditions. In this case:

$$
E F=\frac{h_{g}^{\prime} \text { with ultrasound }}{h_{g}^{\prime} \text { without ultrasound }}
$$

Owing to values of this enhancement factor given in Table 2 (which range from 1.35 using $20 \mathrm{kHz}$ ultrasound up to $2.04 \mathrm{using}$
$800 \mathrm{kHz}$ ultrasound), it might also be concluded that the presence of the ultrasonic field always results in an enhancement of the overall heat exchange transfer coefficient of the coil. It still remains difficult to compare these values because they were obtained under different operating conditions of ultrasonic power.

\section{Influence of the Flow Rate}

Measurements were performed at $1.6 \mathrm{MHz}$ with a significant flow rate variation (from 7 to $190 \mathrm{~L} \cdot \mathrm{h}^{-1}$ ). The corresponding results, reported in Table 2 and Figure 4, confirm the trends observed at $800 \mathrm{kHz}$. In addition, it can been seen that increasing the coil flow rate allows an increase of the enhancement factor (EF). This result can be explained by comparing the three heat transfer resistances. The internal heat transfer resistance depends on the flow rate. The conduction term through copper is constant and can be neglected. The external heat transfer resistance can have two values, depending on whether the ultrasound power is switched on or off. Then, for low flow rates, even if the external heat transfer resistance is low, the high internal heat transfer resistance is limiting and the EF is low. Increasing the flow rate, however decreases the internal heat transfer resistance so that the enhancement can be detected. A limit appears as the internal heat transfer resistance becomes very low and can be neglected, as illustrated in Figure 4.

\section{Influence of the Ultrasonic Power}

According to experiments 3 and 4 , a comparison can be made for experiments carried out with the same cooling water flow

Table 2 Experimentally determined overall heat transfer coefficients of the coil with and without ultrasound and corresponding enhancement factors

\begin{tabular}{|c|c|c|c|c|c|c|}
\hline $\mathrm{N}^{\circ}$ & $\begin{array}{l}\text { Frequency } \\
(\mathrm{kHz})\end{array}$ & Ultrasonic power $(\mathrm{W})$ & $\begin{array}{l}\text { Flow rate } \\
\left(\mathrm{L} \cdot \mathrm{h}^{-1}\right)\end{array}$ & $\begin{array}{l}h_{g}^{\prime} \text { without ultrasound } \\
\left(\mathrm{W} \cdot \mathrm{m}^{-2} \cdot \mathrm{K}^{-1}\right)\end{array}$ & $\begin{array}{l}h_{g}^{\prime} \text { with ultrasound } \\
\left(\mathrm{W} \cdot \mathrm{m}^{-2} \cdot \mathrm{K}^{-1}\right)\end{array}$ & $E F$ (Enhancement factor) \\
\hline 1 & 800 & 57.6 & 141 & 582.3 & 1079.9 & 1.85 \\
\hline 3 & 641 & 57.6 & 141 & 582.3 & 976.5 & 1.68 \\
\hline 4 & 641 & 109 & 141 & 582.3 & 1137.6 & 1.95 \\
\hline 5 & 285 & 30.1 & 141 & 581 & 1083 & 1.86 \\
\hline 8 & 1600 & 42.3 & 24.5 & 556 & 680 & 1.22 \\
\hline 9 & 1600 & 42.3 & 34.7 & 646 & 934 & 1.45 \\
\hline 10 & 1600 & 42.3 & 55 & 489 & 778 & 1.59 \\
\hline 11 & 1600 & 42.3 & 125.1 & 494 & 809 & 1.64 \\
\hline 12 & 1600 & 42.3 & 160 & 464 & 727 & 1.57 \\
\hline 13 & 1600 & 42.3 & 190 & 430 & 732 & 1.7 \\
\hline
\end{tabular}




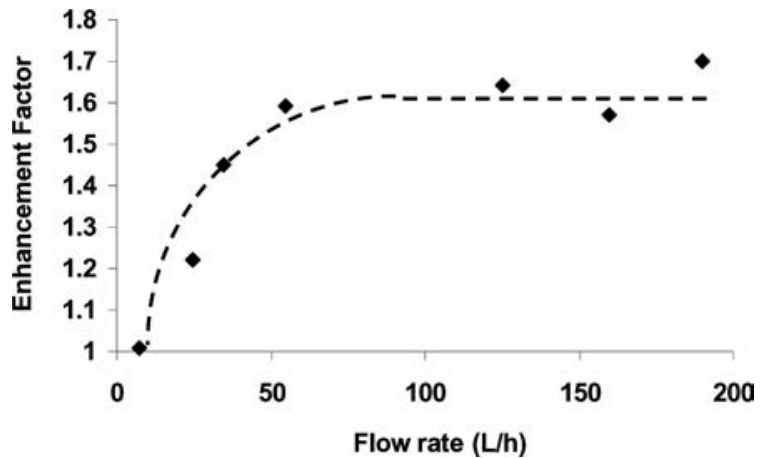

Figure 4 Influence of the flow rate on the enhancement factor $(f=1600 \mathrm{kHz}$, $W=42.3 \mathrm{~W})$.

rate but using two different ultrasonic powers. Owing to values reported in Table 2, increasing ultrasonic power leads to an increase of the overall heat transfer coefficient of the coil. Thus, the EF increase from 1.68 to 1.95 illustrates that the enhancement due to ultrasound increases with the input power.

\section{CONCLUSION}

In this work, it has been shown that the heat transfer between a cooling flow and a liquid inside a vessel can be greatly increased by applying an ultrasonic field. The influence of ultrasonic vibrations on the rate of decrease of the bath temperature allowed the quantitative deduction of the increase of the heat transfer coefficient through an enhancement factor. This result, already demonstrated in previous studies with low-frequency waves, has been extended to the high-frequency range (up to $1600 \mathrm{kHz}$ ). For the highest frequency, the influence of the flow rate on the enhancement factor has been measured. This preliminary study clearly demonstrates the capacity of ultrasound to be used in thermal as well as chemical processes, and such methods could be of a great interest in batch processes.

Future stages of this work will be carried out under specific operating conditions for which it is expected that no cavitation will occur. This will also help distinguish the contribution of mechanisms induced by cavitation and acoustic streaming on the observed enhancement.

\section{NOMENCLATURE}

$C_{p} \quad$ water-specific heat capacity, $\mathrm{J} \cdot \mathrm{kg}^{-1} \cdot \mathrm{K}^{-1}$

$h_{g} \quad$ heat transfer coefficient at the external wall of the ultrasonic reactor, $\mathrm{W} \cdot \mathrm{m}^{-2} \cdot \mathrm{K}^{-1}$

$h_{g}^{\prime} \quad$ overall heat transfer coefficient of the coil, $\mathrm{W} \cdot \mathrm{m}^{-2} \cdot \mathrm{K}^{-1}$

$m$ mass of water contained in the ultrasonic reactor, $\mathrm{kg}$

$S_{\text {ext }} \quad$ external exchange surface of the ultrasonic reactor, $\mathrm{m}^{2}$

$S_{\text {ref }}$ heat exchange surface of the coil, $\mathrm{m}^{2}$

$T$ temperature of water initially contained inside the ultrasonic reactor, ${ }^{\circ} \mathrm{C}$ $t$ time, $\mathrm{s}$

$T_{\text {ext }} \quad$ temperature of ambient air, ${ }^{\circ} \mathrm{C}$

$T_{\text {ref }}$ average temperature (inlet and outlet) of cooling water in the coil, ${ }^{\circ} \mathrm{C}$

$T_{0} \quad$ initial temperature, ${ }^{\circ} \mathrm{C}$

$W \quad$ thermal power induced by ultrasound, $W_{c a l}$

\section{REFERENCES}

[1] Boucher, R. M. G., Sonochemistry at Low and High Ultrasonic Frequencies, British Chemical Engineering Journal, vol. 15, no. 3, pp. 363-367, 1970.

[2] Bergles, A. E., Survey and Evaluation of Techniques to Augment Convective Heat and Mass Transfer, in Progress in Heat and Mass Transfer, vol. 1, eds. U. Grigull and E. Hahne, pp. 331-424, Pergamon Press, London, 1969.

[3] Wong, S. W., and Chon, W. Y., Effects of Ultrasonic Vibrations on Heat Transfer to Liquids by Natural Convection and by Boiling, AIChE Journal, vol. 15, no. 2, pp. 281-288, 1969.

[4] Yukawa, H., Hoshino, T., and Saito, H., The Effect of Ultrasonic Vibrations on Free Convective Heat Transfer from Heated Wire to Water, Heat Transfer Japanese Research, vol. 5, no. 1, pp. 37-49, 1976.

[5] Yukawa, H., Hoshino, T., and Saito, H., Effect of Ultrasonic Vibration on Free Convective Heat Transfer from an Inclined Plate in Water, Heat Transfer Japanese Research, vol. 5, no. 4, pp. 1-16, 1976.

[6] Iida, Y., Tsutsui, K., Ishii, R., and Yamada, Y., Natural-Convection Heat Transfer in a Field of Ultrasonic Waves and Sound Pressure, Journal of Chemical Engineering of Japan, vol. 24, no. 6, pp. 794796, 1991.

[7] Komarov, S., and Hirasawa, M., Enhancement of Gas Phase Heat Transfer by Acoustic Field Application, Ultrasonics, vol. 41, no. 4, pp. 289-293, 2003.

[8] Oh, Y. K., Park, S. H., and Cho, Y. I., A Study of the Effect of U1trasonic Vibrations on Phase-Change Heat Transfer, International Journal of Heat and Mass Transfer, vol. 45, no. 23, pp. 4631-4641, 2002.

[9] Bonekamp, S., and Bier, K., Influence of Ultrasound on Pool Boiling Heat Transfer to Mixtures of the Refrigerants R23 and R134a., Int. J. Refrig., vol. 20, no. 8, pp. 606-615, 1997.

[10] Melkumov, U., and Kurbanov, K., Use of Ultrasound for Intensification of Heat Transfer Process in Heat Exchangers, Proc. International Congress of Refrigeration, Washington, DC, vol. 4, pp. 1-5, 2003.

[11] Yamashiro, H., Takamatsu, H., and Honda, H., Effect of Ultrasonic Vibrations on Transient Boiling Heat Transfer during Rapid Quenching of a Thin Wire in Water, Journal of Heat Transfer, vol. 120, no. 1, pp. 282-286, 1998.

[12] Renaudin, V., Etude et Caractérisation de la Zone Réactionnelle et de la Répartition Énergétique dans un Réacteur á Ultrasons, Ph.D. thesis, Université de Savoie, 1994.

[13] Boldo, P., Pétrier, C., and Gondrexon, N., New Operating Method Improves Calorimetric Measurement of Ultrasonic Power, Proc. 9th Meeting of the European Society of Sonochemistry, Badajoz, Spain, pp. 147-148, 2004. 